\title{
ÉDIPO E NORONHA: UM MITO DO ESPLENDOR À SARJETA
}

Resumo

O mito de Édipo possui uma longa trajetória de recriações ao longo da história do teatro ocidental, cada uma delas dialogando com seu momento histórico. Partindo da teorização de Erich Auerbach em Mimesis, este trabalho compara esse mito tal como expresso nas tragédias Édipo rei e Édipo em Colono, de Sófocles, de um lado, e Os sete gatinhos, de Nelson Rodrigues, de outro, mostrando as diferenças de estatura dos dois protagonistas nas duas peças antigas e na moderna.

\section{Palavras-chave:}

Mito. Édipo. Antigo e Moderno. Ser Humano. 


\title{
ÉDIPO E NORONHA: UM MITO DO ESPLENDOR À SARJETA
}

\author{
Adriano de Paula Rabelo (USP)'
}

\footnotetext{
${ }^{1}$ Doutor em Literatura Brasileira pela Universidade de São Paulo; Pós-doutorado em Teoria Literária pela Universidade Estadual de Campinas; Pós-doutorado em História pela Universidade de São Paulo. E-mail: aprabelo@hotmail.com.
}

Erich Auerbach (2011), em seu livro Mimesis: A representação da realidade na literatura ocidental, mostra como as literaturas do Ocidente passaram todas, ao longo dos últimos três mil anos, por um processo de dissolução da doutrina clássica de representação da realidade, tendo desenvolvido, ao longo dos séculos, formas que as aproximavam cada vez mais do cotidiano. De tal modo que, na era moderna, no âmbito do Renascimento, surge aquele que se tornaria o gênero narrativo por excelência, o romance. Com ele a vida comum seria analisada em todos os seus aspectos.

Na medida em que o homem foi perdendo a centralidade no universo e diminuindo de importância em relação às superestruturas do mundo, as camadas sociais desprivilegiadas econômica, social e politicamente foram se tornando objeto de representação na literatura. Essa incorporação trouxe consigo um correspondente rebaixamento do nível de linguagem e uma limitação cada vez maior do raio de ação das figuras humanas. 
A epopeia grega, que exerceu papel central na educação do cidadão da polis, abarcava todo o conhecimento da época. Tinha como uma de suas figuras principais o astuto Ulisses, heróico rei de Ítaca, arrojado chefe militar que decidiu a guerra de Tróia com seus estratagemas, realizador de proezas espetaculares, protegido pela deusa Atena, falante de uma linguagem nobre, centro absoluto do universo e "medida de todas as coisas"; em suma, um homem completo. Já a narrativa de feição moderna, especialmente depois do romantismo, é pródiga em apresentar seres humanos impotentes, alienados, indecisos, cínicos, zombeteiros, asquerosos, feios, solitários, abandonados, aniquilados, enredados na burocracia, falantes de uma linguagem coloquial, fragmentada, sussurrada ou que nada significa, seres que muitas vezes não sabem nem sequer o que desejam nem como agir. A dramaturgia contemporânea reflete perfeitamente essa transformação.

Este texto faz um paralelo entre a figura de Édipo, em especial nas versões recriadas por Sófocles nas tragédias Édipo rei e Édipo em Colono, e "Seu" Noronha, protagonista da peça Os sete gatinhos, de Nelson Rodrigues, mostrando como, em muitos aspectos, o personagem brasileiro é uma recriação do grego; uma recriação, para além de rebaixada, degradada.

\section{Confluências}

Édipo e "Seu” Noronha são patriarcas de suas famílias, cujos tamanhos são semelhantes. $\mathrm{O}$ aristocrata grego teve dois filhos e duas filhas, e o pequeno funcionário brasileiro teve cinco filhas, sendo que apenas quatro delas moravam inicialmente em sua casa.

Quando a ação se inicia em Édipo rei, a cidade de Tebas debate-se na peste, o que faz o mandatário enviar seu cunhado Creonte até o oráculo de Delfos, a fim de saber como lidar com aquela desgraça aparentemente inexplicável. Com isso, todos tomam conhecimento de que a causa de tudo é a presença, entre os tebanos, do assassino de Laio, que tinha de ser descoberto e posto para fora da cidade. Édipo, en- tão, compromete-se publicamente a encontrar o portador da maldição. Do mesmo modo, na casa suburbana de "Seu" Noronha grassa uma espécie de peste moral que faz com que suas filhas, exceto a caçula, que mora num colégio interno, se percam na prostituição e jamais se casem. Adepto da igreja teofilista, uma seita radical do espiritismo, médium ele mesmo, Noronha também consulta um oráculo ao receber o espírito do Dr. Barbosa Coutinho, médico do imperador D. Pedro II. Este lhe revela que há alguém que corrompe suas filhas, e esse alguém, um homem que chora por um olho só, precisa ser descoberto e assassinado. Tal como Édipo, "Seu” Noronha dá início a um inquérito para descobrir o causador da pestilência em seu lar, deixando de prontidão seu punhal de prata. Logo saberá que a situação é muito pior que imagina, pois Silene, a caçula, última esperança de pureza na família, é expulsa do colégio interno depois de matar uma gata prenhe a pauladas. Em seguida se revelará também que a adolescente está grávida. A corrupção, portanto, é total e a todos abarcou.

Édipo envolve toda a cidade na busca ao responsável pelo miasma que paira sobre Tebas, bem como "Seu" Noronha envolve toda a família na caça ao culpado pela desgraça de suas filhas. No meio desse processo, o tirano grego confronta o adivinho Tirésias. Este lhe assevera que o assassino está mais perto do que se imagina, que ele matou o próprio pai e se casou com a própria mãe, com quem teve seus filhos, que essa pessoa... é o próprio rei. Em Os sete gatinhos, a filha Arlete, que também possui dons mediúnicos, exerce o papel de Tirésias ao receber o espírito de primo Alípio, que morrera pouco tempo antes. Através dela, já no final da peça, haverá uma revelação correspondente à recebida por Édipo: "Velho! Você é o demônio que chora por um olho só!" (RODRIGUES, 2003, p. 877).

Édipo suspeita que há uma conspiração liderada por seu cunhado Creonte para tirá-lo do poder. A rainha Jocasta, que não acredita nas previsões e adivinhações, busca tranquilizar Édipo, contando-lhe que seu primeiro marido 
recebera do oráculo a revelação de que seria morto pelo próprio filho. No entanto, ao narrar as circunstâncias da morte de Laio, em vez de tranquilizá-lo, deixa-o ainda mais inquieto. "Seu" Noronha, por sua vez, quando recebe Silene de volta, pensa haver uma conspiração de todos contra a pureza virginal da filha: "Nenhum colégio é digno de ti! E todo mundo tem inveja da tua pureza. Humanidade cachorra!" (RODRIGUES, 2003, p. 854). Porém, a confirmação de que a barbaridade cometida contra a gata é verdadeira e, principalmente, de que a caçula está de fato grávida também representam o golpe de misericórdia nas ilusões de "Seu" Noronha.

Por fim, a verdade é esclarecida em sua totalidade, e Édipo descobre que o portador da maldição buscado por ele era ele mesmo. Jocasta, sua mãe e esposa, suicida-se antes que Édipo fure os próprios olhos e abandone Tebas. Inicialmente heroico, poderoso e arrogante, transforma-se então num desgraçado a vagar pela Grécia amparado por sua filha e meia-irmã Antígona, aceitando seu destino inexorável. Por seu turno, "Seu" Noronha, depois de um pacto para que suas filhas lhe tragam o responsável pela perdição de Silene, recebe em sua casa, conduzido por Aurora, o malandro Bibelot, pai do filho esperado pela adolescente, matando-o com o punhal de prata enquanto ele dormia. Contudo, logo se verifica que, ao receber a punhalada fatal, Bibelot chora pelos dois olhos. Com isso, as filhas se dão conta - o que é confirmado pelo espírito de primo Alípio - de que Noronha é verdadeiro o responsável por sua perda. Só lhes resta, então, cometer o parricídio libertador. De tirano doméstico que tratava a mulher e as filhas aos gritos e bofetadas, o patriarca dos Noronha se transforma num pobre-diabo que chora por um olho só antes de ser trucidado.

\section{Contrastes}

Os contrastes entre os dois personagens são obviamente bem mais pronunciados, exprimindo sua estatura humana de acordo com o momento histórico em que se situam. Ainda assim, as baixezas de "Seu" Noronha, que contém todo o grotesco de tantos personagens modernos, correm paralelas às grandezas de Édipo e são seu reverso.

Édipo é rei de Tebas, uma das mais poderosas cidades-estado da Hélade. É filho de Laio e seria o herdeiro legítimo do trono, caso não fosse vítima da maldição que pesava sobre sua família. Realizou uma proeza heroica ao salvar a cidade do flagelo da esfinge. É dotado de muitos talentos e possui uma inteligência notável, a ponto de ter sido o único a resolver o enigma proposto pelo monstro que aterrorizava os tebanos. Tem uma esposa bonita e nobre, além de filhos perfeitos. No começo da peça de Sófocles, é apresentado em toda a magnificência de seu poder. É um homem honesto e deseja realmente saber a verdade, comprometendo-se diante dos cidadãos de Tebas a envidar todos os esforços para que ela apareça. Muito bem articulado, fala uma linguagem elevada e muito expressiva. Mantém sua dignidade mesmo na desgraça, depois da descoberta de que matou o pai, casou-se com a mãe e com ela procriou. Depois do suicídio de tons heroicos de Jocasta, ele fura os próprios olhos e deixa a cidade, perambulando pela Grécia. Acompanhado por sua filha Antígona, torna-se um velho sábio e obediente aos oráculos depois de todos os seus sofrimentos. Tanto que o próprio oráculo revela publicamente que o lugar onde Édipo estiver será não somente bem-aventurado como vencerá a guerra fratricida que se desencadeou após sua partida, na disputa pelo trono. Isso faz com que tanto Etéocles quando Polinices, seus filhos beligerantes que o haviam abandonado, tomem medidas para atraí-lo. No entanto, revoltado por seus próprios filhos haverem lhe virado as costas, Édipo roga-lhes a maldição de que ambos se matarão um ao outro, o que de fato acontece. Por fim, solicita a proteção de Teseu, rei de Colono, nos arredores de Atenas, onde é recebido com hospitalidade e onde termina seus dias numa morte gloriosa, sendo arrebatado pelos deuses aos pés do monte Olimpo e expiando seus crimes involuntários. É o que o mesmo Só- 
focles nos conta na tragédia Édipo em Colono.

Tendo, como se viu, um percurso em linhas gerais bastante semelhante ao de Édipo, "Seu" Noronha contrasta profundamente com o desafortunado rei tebano em sua estatura humana e sua dignidade. Já no começo da peça, ele e sua família são apresentados na quase absoluta sordidez em que vivem, no Grajaú, desprestigiado subúrbio do Rio de Janeiro. Até mesmo a atividade profissional de Noronha funciona como um símbolo de sua baixeza. Ele tem vergonha de ser contínuo, palavra que no universo de Os sete gatinhos chega a ser usada como um insulto. Pai despótico e moralista sem moral, agride fisicamente as filhas, fala aos gritos e faz uso de uma linguagem bastante grosseira. Não consegue conter nem mesmo as falas de teor racista. Sua grande proeza teria sido preservar a virgindade e a pureza da filha caçula, a fim de proporcionar-lhe um casamento nos moldes burgueses e salvaguardar sua família de um apodrecimento completo, mas também nisso ele não somente fracassa como é a causa desse fracasso. Sua esposa, D. Aracy, chamada por ele de Gorda, está muito longe de ser uma Jocasta. Para além do descuido físico, com suas "varizes e suor azedo" (RODRIGUES, 2003, p. 860), apresenta problemas afetivos graves, que se exprimem nos desenhos obscenos e palavrões que rabisca no banheiro da casa, como forma de sublimação pelo desinteresse sexual do marido. Em virtude da maldição que pesa sobre a família, suas filhas todas se perdem na prostituição e se tornam inválidas para uma vida "normal" na sociedade em que se inserem. Pior, com a descoberta da perda também da caçula, o patriarca resolve assumir a degeneração total ao inaugurar, em seu próprio lar, um bordel de filhas.

"Seu" Noronha aterroriza o diretor do colégio da caçula, induz o médico da família a ser o primeiro cliente de Silene (levando-o a suicidar-se depois de mergulhar na sordidez de possuir uma menina da mesma idade de sua filha) e mata Bibelot, quando este dormia, na busca pelo homem que chora por um olho só. Atos muito distintos daqueles de Édipo, que mata Laio e quase toda a sua caravana para pre- servar a dignidade pessoal depois de ser ofendido e desafiado. Atos ainda mais distintos do heroico enfrentamento e morte da esfinge.

Embora a ambição dos filhos homens de Édipo os tenha levado a liderarem uma guerra fratricida em que um mataria o outro, realizando uma maldição do próprio pai, eles continuam sendo figuras grandiosas. Suas filhas Antígona e Ismene, por sua vez, dão-lhe o sustentáculo de que necessita quando, cego, passa a vagar pelas estradas da Grécia. Já as filhas de Noronha o abominam e o ofendem o quanto podem, tendo com ele uma relação extremamente conflituosa em que a violência de parte a parte dá o tom.

O principal contraste entre Édipo e "Seu” Noronha, porém, está na forma como terminam suas vidas. Se o grego teve uma morte sublime aos pés do Olimpo, disputado pelos homens e misteriosamente capturado pelos deuses, o brasileiro morre de forma ignominiosa, tal como viveu. Fechado num círculo de filhas após se revelar que ele é o homem que chora por um olho só, aquele que as forçou a se prostituírem, obrigando-as a viver à margem do sistema social, é assassinado por elas com o punhal de prata reservado para dar cabo do portador do mal que corrompia sua família. Tal assassinato, que em muitos aspectos lembra o parricídio primordial teorizado por Freud (2015) em Totem e tabu, é o que vai permitir às filhas enfim humanizar-se verdadeiramente e conquistar sua independência para poderem gozar a vida e se realizarem como seres humanos fora de casa.

\section{O trono e a polis, a casa e a rua}

Tanto na tragédia grega como na brasileira há uma forte correlação entre dois espaços, um público e outro privado. Eles também marcam a representação da grandeza, de um lado, e da abjeção, de outro. Se Édipo rei e Édipo em Colono estão centradas na vida pública e o grande personagem da antiguidade deve cegar-se, viver uma vida errante e morrer longe de Tebas para preservar a cidade, Os sete gatinhos está centrada na vida privada e o repugnante personagem moderno deve morrer assassinado para que se 
preserve um mínimo de humanidade por parte dos membros de sua família.

Ao matar Laio sem saber que ele era seu pai, num embate familiar e do âmbito doméstico, Édipo causou enorme problema público ao fazer vagar o trono de Tebas. Porém ele mesmo, ainda na ignorância das consequências de seus atos, resolveu a questão ao matar a esfinge, pondo fim a uma calamidade pública, tornando-se o novo rei e casando-se com Jocasta. Com isso, solucionou o problema da sucessão no poder da cidade e reconstituiu o lar da realeza. Tão bem o fez que de seu enlace com a própria mãe resultaram quatro filhos. Durante muitos anos, aparentemente resolvida a integridade da família real e do poder, Tebas floresceu, vivendo um período de paz e prosperidade. No entanto, um dia a peste passa a assolar a cidade, apresentando-se como um problema público que precisava ser enfrentado sob a liderança do rei. Ante a revelação do oráculo de que o portador da maldição estava entre os tebanos, Édipo se compromete a encontrar o criminoso. Sua investigação revelará que tal criminoso não somente estava dentro da cidade, mas também dentro de sua casa. Era o próprio Édipo, patriarca de seu oikos, rei de Tebas. De modo que, para salvar a comunidade tebana, seria preciso destruir o lar de seu líder, onde residia a maldição revelada pelo oráculo. Jocasta suicida-se, Édipo cega-se e deixa a cidade, seus filhos se matam reciprocamente na luta pelo poder, suas filhas o acompanham e partilham suas desditas. Ironicamente, depois do esgarçamento de sua família e de sua partida de Tebas, o próprio oráculo revela que o local onde Édipo estiver obterá a benevolência dos deuses. Isso desencadeia esforços para atraí-lo e reconstituir a paz pública numa cidade agora em guerra. Apartado das coisas públicas, no entanto, ele vive seus últimos tempos acompanhado pela filha Antígona, além de receber suporte da caçula Ismene. A dialética tensa entre o âmbito da cidade-estado e do lar, da qual Édipo está no centro, só encontra resolução com sua morte afortunada ao final de uma vida marcada por tantos infortúnios.

Já no caso de "Seu" Noronha percebe- -se que essa dialética se dá entre os domínios da casa e da rua. Sob o império de uma mentalidade em que a moral, ou melhor, o moralismo define o valor das vidas humanas, a casa é o lugar onde ocorre um maior controle das relações sociais, que são pessoalizadas ao extremo. Nela há uma clara hierarquia em cujo topo está o homem e o mais velho, tal como nas relações familiares arcaicas. Isso permite que "Seu" Noronha se comporte como um déspota em miniatura, ridicularizando a esposa, surrando as filhas, gritando com todos como exercício de dominação. Se é humilhado no espaço exterior, busca descontar toda a sua frustração nos familiares e naqueles que visitam seu lar. Ainda assim, tem a necessidade de romper com o disfarce que usa na rua, pedindo que o chamem de contínuo ou provocando as filhas para que elas o façam na forma de uma ofensa. A propósito, a rua é o lugar onde reina a impessoalidade. Por ela transitam os marginais, as prostitutas, os criminosos, aqueles que se encontram fora do sistema ao qual "Seu" Noronha almeja pertencer integralmente. Quando esse mundo desordenado e fora de controle começa a invadir o domus dos Noronha, revela-se toda a degradação da casa. D. Aracy rabisca desenhos obscenos e palavrões nas paredes do banheiro, fazendo com que ele adquira toda a personalidade dos banheiros públicos. O papel higiênico, proibido na casa, é um índice da sujeira que ali grassa. Os que vêm de fora - "Seu" Saul, Dr. Portela, Dr. Bordalo e Bibelot - são ofendidos, aterrorizados, corrompidos ou mortos no local. As filhas, que possuíam empregos de fachada, aparentando pessoas comuns no âmbito exterior, exibem ali sua realidade de mulheres públicas. Porém, a revolta humanizadora tem início quando "Seu" Noronha decide transformar a casa num bordel de filhas, depois da perda definitiva das ilusões de pureza da família, quando Silene volta grávida do espaço exterior, após matar a gata prenhe a pauladas. Ao assumir a completa abjeção, pretendendo transformar seu lar numa "casa de portas abertas", totalmente permeável à degeneração das ruas, o pai se mostra como o portador da maldição que paira sobre a família. Portanto, 
precisa ser eliminado para que as forças vitais da ordem voltem a reinar depois do caos que ali se instalou, numa espécie de eterno retorno nietzschiano. É o que se confirma com a intervenção final do espírito de primo Alípio, que ordena o assassinato de "Seu" Noronha.

\section{Efeitos}

Se a história de Édipo, tal como apresentada nas duas primeiras peças da trilogia tebana, de Sófocles, provoca "terror e piedade", tendo por efeito "a purificação dessas emoções", conforme a famosa definição da tragédia por Aristóteles (1966, p. 74), pode-se dizer que a de "Seu" Noronha, o personagem de Nelson Rodrigues, provoca repulsa e confere sentido moral a sua punição. $\mathrm{O}$ dramaturgo brasileiro - que considerava "legítimo unir elementos atrozes, fétidos ou o que seja, numa composição estética", podendo "extrair poesia de coisas aparentemente contraindicadas" (RODRIGUES, 1949, p. 13) - não somente previa como deleitava-se com as reações suscitadas por seus trabalhos. Se Édipo é o homem como "medida de todas as coisas", conforme o célebre aforismo de Protágoras, ele está no centro do universo, é aquele que questiona, julga, analisa, avalia, invalida, chancela, relativiza ou absolutiza as coisas do mundo. "Seu" Noronha, por sua vez, é o homem medido por todas as coisas, pertencente a um mundo habitado por bilhões de pessoas, enredado em estruturas burocráticas para as quais ele é apenas um número nas estatísticas, desvalorizado por não pertencer a um estrato social ocupado por pessoas "que contam". No âmbito do cristianismo tardio em que se desenrola sua história, sua destruição é vista como consequência da culpa ou responsabilidade resultante de suas ações conscientes, comovendo-nos muito menos que a queda de Édipo. Na não identificação com a desgraça de "Seu" Noronha, em vez de sermos arrebatados por "terror e piedade", muito mais refletimos sobre as condições de vida precárias que contribuem para alguns descaminhos morais das classes baixas, pressionadas economicamente, desvalorizadas so- cialmente e inseridas num universo arcaico de crenças.

Por fim, uma reflexão sobre a realidade contemporânea, que já é muito diferente daquela dos anos 1950, quando Nelson Rodrigues escreveu Os sete gatinhos. Nestes tempos da chamada pós-verdade, das Fake News e de um paupérrimo debate público-privado nas redes sociais, feito com base na ignorância agressiva, é muito possível que vejamos surgir, a qualquer momento, uma reatualização do mito de Édipo na forma de um canalha ou imbecil da vida pública. Ou de alguém que sintetize essas "qualidades". Hoje em dia canalhas e imbecis não apenas abundam nas posições de poder, mas também fazem questão de exibir publicamente sua ignomínia e sua estultice como se elas fossem virtudes. Seria catártico assistir à queda de um Édipo assim. Ou será que figuras assim são propriedade inalienável da comédia? 


\section{REFERÊNCIAS}

ARISTÓTELES. Poética. Tradução de Eudoro de Sousa. Porto Alegre: Globo, 1966.

AUERBACH, Erich. Mimesis: A representação da realidade na literatura ocidental. Tradução de George Bernard Sperber. São Paulo: Perspectiva, 2011.

FREUD, Sigmund. Totem e tabu. Tradução de Paulo César de Souza. São Paulo: Penguin \& Companhia das Letras, 2015.

RODRIGUES, Nelson. Teatro completo. Rio de Janeiro: Nova Aguilar, 2003.

21, out. 1949.

Teatro desagradável. Dionysos, Rio de Janeiro, n. 1, p. 16-

SÓFOCLES. A trilogia tebana. Tradução de Mário da Gama Kury. Rio de Janeiro: Zahar, 1998.

SOUZA, José Cavalcante de (org.). Os pré-socráticos: Fragmentos, doxografia e comentários (Coleção Os Pensadores). Seleção de textos e supervisão de José Cavalcante de Souza. (Traduções de José Cavalcante de Souza, Anna Lia Amaral de Almeida Prado, Ísis Lana Borges, Maria Conceição Martins Cavalcante, Remberto Francisco Kuhnen, Rubens Rodrigues Torres, Filho, Carlos Ribeiro de Moura, Ernildo Stein, Arnildo Devegili, Paulo Frederico Flor, Wilson Regis). São Paulo: Nova Cultural, 2000. 


\begin{abstract}
The myth of Oedipus has had an extensive history of recreation along the history of the Western theatre, with each one of them expressing its historical time. Departing from Erich Auerbach's theory as exposed in his book Mimesis, this work compares Oedipus myth as exposed in the tragedies Oedipus rex and Oedipus at Colonus by Sophocles, on the one hand, and The seven kittens by Nelson Rodrigues, on the other hand. It shows the stature contrasts between these two characters in the two ancient plays, as well as the modern one.
\end{abstract}

\title{
Keywords
}

Myth. Oedipus. Ancient and Modern. Human Being.

\section{Resumen}

El mito de Edipo posee una larga trayectoria de recreaciones a lo largo de la historia del teatro occidental, cada una de ellas dialogando con su momento histórico. A partir de la teorización de Erich Auerbach en Mimesis, este trabajo compara ese mito tal como se expresa en las tragedias Edipo rey y Edipo en Colono, de Sófocles, por una parte, y Los siete gatitos, de Nelson Rodrigues, por otro, mostrando las diferencias de estatura de los dos protagonistas en las dos obras antiguas y en la obra moderna.

\section{Palabras clave}

Mito. Edipo. Antiguo y Moderno. Ser Humano. 